\title{
Predictors of Survival among Pediatric and Adult Ependymoma Cases: A Study Using Surveillance, Epidemiology, and End Results Data from 1973 to 2007
}

\author{
E. Susan Amirian ${ }^{a}$ Terri S. Armstrong ${ }^{b}$ Kenneth D. Aldape ${ }^{c}$ Mark R. Gilbert $^{d}$ \\ Michael E. Scheurera, e \\ ${ }^{a}$ Dan L. Duncan Cancer Center, Baylor College of Medicine, b Department of Integrative Nursing Care,

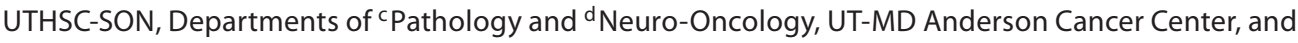 \\ e Department of Pediatrics, Baylor College of Medicine, Houston, Tex., USA
}

\section{Key Words}

Ependymoma $\cdot$ Brain cancer $\cdot$ Survival analyses $\cdot$ Brain tumor $\cdot$ SEER program

\begin{abstract}
Background: Despite previous research, prognostic factors for ependymoma remain relatively controversial. The purpose of our study was to examine demographic, clinical, and tumor attributes as potential predictors of survival using Surveillance, Epidemiology, and End Results (SEER) program data (1973-2007). Methods: All ependymoma (ICD-O-3 code 9391) and anaplastic ependymoma cases (ICD-O-3 code 9392) with complete data ( $n=2,369$ and $n=319$, respectiveIy) were included from SEER. Predictive Cox regression models were built separately among pediatric and adult cases. Recursive partitioning was used to corroborate results from regression models. Results: Among pediatric cases, tumor characteristics with a significantly increased mortality risk were anaplastic histology (vs. low grade, HR: 1.51, 95\% Cl: 1.04-2.19) and infratentorial tumor location (vs. spinal cord, HR: $3.86,95 \%$ Cl: 1.17-12.77). Among adults, supratentorial tumors were associated with higher mortality hazard (vs. spi-
\end{abstract}

nal cord tumors) than infratentorial tumors (HR: $4.83,95 \% \mathrm{Cl}$ : 3.49-6.68 and HR: $2.41,95 \%$ Cl: 1.79-3.25, respectively). Complete surgical resection of the tumor conferred the most protection among pediatric and adult patients. Conclusion: Our results indicate that treatment type and tumor characteristics are important prognostic factors in patients with ependymoma. However, there may be key differences between pediatric and adult cases regarding how these factors influence survival.

Copyright $\odot 2012$ S. Karger AG, Basel

\section{Introduction}

Ependymomas are rare brain tumors with an annual incidence of 2-4 per million [1-4]. They constitute 3-5\% of adult intracranial gliomas and $8-10 \%$ of childhood tumors of the central nervous system [2, 4-8]. Infratentorial tumors are less common in adults and more prevalent in children, whereas spinal cord tumors have the opposite distribution [6]. Supratentorial tumors occur more frequently in older children and adults, compared to younger children $[7,9]$.

\section{KARGER}

Fax +4161306 1234

E-Mail karger@karger.ch

www.karger.com
(C) 2012 S. Karger AG, Basel

$0251-5350 / 12 / 0392-0116 \$ 38.00 / 0$

Accessible online at:

www.karger.com/ned
Michael E. Scheurer

Dan L. Duncan Cancer Center

Baylor College of Medicine, One Baylor Plaza

MS:BCM305, Houston, TX 77030 (USA)

Tel. +1 713798 5547, E-Mail scheurer@bcm.edu 
Studying prognostic factors among brain tumor patients has always proven to be challenging for numerous reasons. One of the major obstacles is that the rarity of brain tumors often limits case recruitment, resulting in studies with small study populations and low statistical power $[2,6,7,10]$. To boost sample size, some studies have grouped pediatric and adult ependymoma cases together for survival analysis, which may be inappropriate given that prognosticators could differ by age group. Additionally, misclassification of tumor type poses a major problem in ependymoma research (reported to be as high as $60-69 \%)[2,6,11,12]$. Criteria for the diagnosis and grading of ependymoma have long been points of contention among pathologists $[6,7]$, and potentially due to this reason, histology has not consistently been associated with patient prognosis $[2,5,7]$. For these and other reasons, few highly consistent trends have emerged in research on ependymoma prognosis.

However, despite these issues, multiple studies have shown that intracranial tumor location, male sex, and extent of surgical resection may be associated with ependymoma mortality [2, 13-15]. Here, we used data from the Surveillance, Epidemiology, and End Results (SEER) program to corroborate such previous findings and to identify the most important predictors of mortality risk among pediatric and adult cases, using Cox regression and recursive partitioning (both classification and regression trees, CART, and tree-based survival analysis, TBSA).

\section{Materials and Methods}

\section{Case Selection and SEER Data}

The SEER program of the National Cancer Institute is a population-based registry that provides publicly available data on cancer incidence and survival for $28 \%$ of the US population (http://seer.cancer.gov/). We utilized the 1973-2007 SEER dataset (released April 2010), which included 17 registries. The case definition included low-grade (WHO grade II; ICD-O-3 code 9391) and anaplastic ependymomas (WHO grade III; ICD-O-3 code 9392). Data on tumor histology, age at diagnosis, month/year of diagnosis, tumor site, race/ethnicity, sex, vital status, treatment, and survival time were also obtained. Composite variables encompassing all available treatment information were created from the five variables in SEER that contain information on radiation therapy, surgery type, surgery site, and sequence of surgery/radiation.

\section{Statistical Analyses}

Differences in population characteristics, both by tumor histology and between pediatric and adult cases, were compared using $\chi^{2}$ tests. Exploratory, predictive Cox regression models were built separately among pediatric and adult cases, using backwards stepwise selection, to identify significant predictors of mortality hazard in each group. Potential predictors considered for inclusion in the models were age at diagnosis, sex, race/ethnicity, tumor location, extent of surgery, radiation therapy, and tumor histology. Overall survival was used as the outcome of interest for all analyses; however, a post-hoc analysis verified that the results for cause-specific survival were relatively similar, although some effects were attenuated likely due to poor precision related to having fewer failures.

We also conducted CART and TBSA, including the same variables, both to corroborate the results from the Cox models and to provide further insight into which combinations of attributes may have the most profound effects on prognosis. CART and TBSA are powerful data-mining tools that partition the study population into groups that have different risk or survival distributions and help expose hierarchical predictive relationships (and higher-order interactions) [16]. At each level, the tree splits on the basis of an influential predictor to separate individuals into two subgroups (or nodes) that are as different as possible in relation to their distributions of the outcome variable, but each node itself is relatively homogeneous $[16,17]$. The splits continue until the optimal tree is built, which differentiates subgroups of the study population that are at higher risk for the outcome, ideally without overfitting the data. Details on these analytic techniques are provided elsewhere [16-18].

We utilized CART to elucidate the relationship between potential predictors and mortality risk, treating mortality as a dichotomous outcome. Then TBSA was used to examine these predictors with mortality hazard as a time-to-event outcome. Both analyses were conducted separately in children and adults. The Gini improvement measure was used to determine splitting in the CART analysis [17]. For the TBSA, the log-rank statistic was used to identify statistically significant $(\alpha=0.05)$ splits in the dataset until either there were no more significant splits remaining or the nodes reached the minimum size $(\mathrm{n} \geq 50)$. The pruning criterion applied in the CART analysis was the one-standard error rule [17]. No pruning rules were necessary for the TBSA analyses, as these trees were reasonably small due to the minimum node size criterion. Among adults, we selected the first node to be the age variable to help determine whether the prognostic stratifications would differ for older versus younger adults. CART was performed using Salford Predictive Model Builder version 6.6, and TBSA was conducted in Stata version 10.0 (adapted from elsewhere [19]).

\section{Results}

A total of 2,802 ependymomas (2,474 low-grade and 328 anaplastic) were reported to the SEER program (1973-2007), of which 114 were excluded from these analyses for having zero or missing survival time. Of these 114 , only 7 had anaplastic ependymomas. Approximately, $97.5 \%$ of diagnoses were microscopically confirmed. Over half of all cases were diagnosed between 2000 and 2007, partly due to the addition of four registries in 2000 . Only $7 \%$ of all cases were reported in the 1970s. 
Table 1. Population characteristics of SEER dataset 1973-2007: overall, by histology, and among pediatric $(<18)$ and adult cases

\begin{tabular}{|c|c|c|c|c|c|c|c|}
\hline Characteristic & $\begin{array}{l}\text { Overall } \\
(\mathrm{n}=2,688) \\
\mathrm{n}(\%)\end{array}$ & $\begin{array}{l}\text { Ependymoma } \\
(\mathrm{n}=2,369) \\
\mathrm{n}(\%)\end{array}$ & $\begin{array}{l}\text { Anaplastic } \\
(\mathrm{n}=319) \\
\mathrm{n}(\%)\end{array}$ & $\begin{array}{l}\mathrm{p} \\
\text { value }\end{array}$ & $\begin{array}{l}\text { Pediatric } \\
(\mathrm{n}=782) \\
\mathrm{n}(\%)\end{array}$ & $\begin{array}{l}\text { Adult } \\
(\mathrm{n}=1,906) \\
\mathrm{n}(\%)\end{array}$ & $\begin{array}{l}\mathrm{p} \\
\text { value }\end{array}$ \\
\hline$<5$ years & $392(14.6)$ & $293(12.4)$ & $99(31.0)$ & & & & \\
\hline 5-17 years & $390(14.5)$ & $312(13.2)$ & $78(24.5)$ & & & & \\
\hline $18-59$ years & $1,539(57.3)$ & $1,416(59.8)$ & $123(38.6)$ & & & & \\
\hline Sex & & & & 0.69 & & & 0.006 \\
\hline Male & $1,446(53.8)$ & $1,271(53.7)$ & $175(54.9)$ & & $453(57.9)$ & $993(52.1)$ & \\
\hline Female & $1,242(46.2)$ & $1,098(46.4)$ & $144(45.1)$ & & $329(42.1)$ & $913(47.9)$ & \\
\hline Race & & & & $<0.001$ & & & \\
\hline Non-Hispanic White & $1,903(70.8)$ & $1,712(72.3)$ & $191(59.9)$ & & $473(60.5)$ & $1,430(75.0)$ & \\
\hline Black & $207(7.7)$ & $179(7.6)$ & $28(8.8)$ & & $88(11.3)$ & $119(6.2)$ & \\
\hline Infratentorial & $600(22.3)$ & $518(21.9)$ & $82(25.7)$ & & $266(34.0)$ & $334(17.5)$ & \\
\hline Supratentorial & $326(12.1)$ & $225(9.5)$ & $101(31.7)$ & & $139(17.8)$ & $187(9.8)$ & \\
\hline Other/NOS sites & $654(24.3)$ & $544(23.0)$ & $110(34.5)$ & & $316(40.4)$ & $338(17.7)$ & \\
\hline Extent of surgery & & & & $<0.001$ & & & 0.02 \\
\hline Debulking (gross total or radical) & $1,119(41.6)$ & $959(40.5)$ & $160(50.2)$ & & $337(43.1)$ & $782(41.0)$ & \\
\hline Subtotal resection & $509(18.9)$ & $442(18.7)$ & $67(21.0)$ & & $141(18.0)$ & $368(19.3)$ & \\
\hline No surgery/biopsy only & $590(22.0)$ & $529(22.3)$ & $61(19.1)$ & & $141(18.0)$ & $449(23.6)$ & \\
\hline Unknown & $470(17.5)$ & $439(18.5)$ & $31(9.7)$ & & $163(20.8)$ & $307(16.1)$ & \\
\hline Radiation therapy & & & & $<0.001$ & & & $<0.001$ \\
\hline Yes & $1,254(46.7)$ & $1,042(44.0)$ & $212(66.5)$ & & $276(35.3)$ & $768(40.3)$ & \\
\hline No & $1,369(50.9)$ & $1,273(53.7)$ & $96(30.1)$ & & $486(62.2)$ & $1,093(57.4)$ & \\
\hline Unknown & $65(2.4)$ & $54(2.3)$ & $11(3.5)$ & & $20(2.6)$ & $45(2.4)$ & \\
\hline
\end{tabular}

Table 1 presents population characteristics overall, by histology, and among pediatric and adult cases. Anaplastic ependymoma cases were more likely to have undergone complete resection and to have been treated with radiation therapy, compared to low-grade cases. Comparing children to adults, a higher proportion of pediatric cases had anaplastic tumors and the distribution of sex was more unequal in children. Intracranial tumors were much more prevalent than spinal cord tumors among pediatric cases. Only about $8 \%$ of ependymomas were located in the spinal cord in children, compared to $55 \%$ in adults. The most common tumor site in children was the infratentorial region of the brain.

Hazard ratios from univariable, full, and final Cox proportional hazards regression models are provided separately for pediatric and adult cases (tables 2, 3, re- spectively). The final model for pediatric cases included tumor location, treatment, histology, and age at diagnosis (borderline significant). Tumor location appeared to be a stronger predictor than histology. Having any treatment beyond subtotal resection alone accorded a protective effect, with the strongest effect being associated with complete resection without radiation.

Among adults, the significant predictors were essentially the same as in the pediatric model, with the exception that a combination variable was not used for radiation/surgery in the adult model because radiation was not significantly predictive of survival after adjustment for covariates. The strongest predictors of survival were age and supratentorial tumor location. Adults $>59$ years of age had a 4.54 times higher mortality hazard than those $<60$ (95\% CI: 3.64-5.66). Those with supratentorial tu- 
Table 2. Hazard ratios from univariable, full, and final Cox regression models among pediatric ependymoma cases

\begin{tabular}{|c|c|c|c|}
\hline Predictor & Univariable & Full model & Final model \\
\hline \multicolumn{4}{|l|}{ Age group } \\
\hline$<5$ years & Ref. & Ref. & Ref. \\
\hline 5-17 years & $0.49(0.37-0.66)$ & $0.72(0.48-1.05)$ & $0.69(0.46-1.00)^{\mathrm{b}}$ \\
\hline \multicolumn{4}{|l|}{ Sex } \\
\hline Female & Ref. & Ref. & \\
\hline Non-Hispanic White & Ref. & Ref. & \\
\hline Black & $1.28(0.83-1.99)$ & $1.39(0.77-2.51)$ & \\
\hline Hispanic & $1.15(0.81-1.63)$ & $1.26(0.83-1.91)$ & \\
\hline Asian and other & $0.78(0.42-1.46)$ & $0.61(0.27-1.34)$ & \\
\hline \multicolumn{4}{|l|}{ Tumor location } \\
\hline Spinal cord & Ref. & Ref. & Ref. \\
\hline Less than GT without radiation & Ref. & Ref. & Ref. \\
\hline Less than GT with radiation & $0.51(0.30-0.85)$ & $0.61(0.36-1.04)$ & $0.63(0.37-1.07)$ \\
\hline GT without radiation & $0.25(0.15-0.43)$ & $0.26(0.15-0.46)$ & $0.28(0.16-0.48)$ \\
\hline GT with radiation & $0.35(0.22-0.55)$ & $0.37(0.23-0.60)$ & $0.38(0.23-0.61)$ \\
\hline \multicolumn{4}{|l|}{ Histology } \\
\hline Low-grade ependymoma & Ref. & Ref. & Ref. \\
\hline Anaplastic ependymoma & $1.44(1.04-1.99)$ & $1.53(1.04-2.24)$ & $1.51(1.04-2.19)$ \\
\hline
\end{tabular}

mors had 4.83 times the mortality risk of those with spinal cord tumors (95\% CI: 3.49-6.68).

A post-hoc analysis in which both final models were further adjusted for decade of diagnosis, in order to account for the diagnostic and therapeutic advances since 1973, yielded similar hazard ratios as those in tables 2 and 3.

The results from CART and TBSA are given in figure 1 for pediatric cases. The CART analysis indicated that among those who received a level of treatment beyond subtotal resection alone, age at diagnosis was the most important predictor of mortality (fig. 1a). The survival tree, however, was more complex, potentially because TBSA accounts for survival time (fig. 1b). If any treatment beyond subtotal resection alone was received, then tumor histology became important. Cases with anaplastic tumors fared worse over time compared to the reference node (HR: 4.51, 95\% CI: 1.90-10.71). Among those with low-grade tumors, individuals with subtotal resection had worse prognosis than those with complete resection. The final split among those with low-grade ependymomas who had complete resection occurred on the basis of race/ethnicity.

Figure 2 displays the CART and TBSA trees for adult cases. The CART indicated that among cases diagnosed before 60 years of age, those who did not undergo radiation therapy had a lower mortality risk than those who did (fig. 2a). Among those who received radiation therapy, individuals with supratentorial tumors had a higher mortality risk than those with ependymomas located elsewhere.

The terminal nodes of the survival tree were based on age, tumor location, histology, surgical margin, and radiation (fig. 2b). The node with the greatest mortality hazard over time was comprised of individuals who were $\geq 60$ years of age and had supratentorial tumors (HR: 26.17, 95\% CI: $17.40-39.37$ vs. reference node). 
Table 3. Hazard ratios from univariable, full, and final Cox regression models among adult ependymoma cases

\begin{tabular}{|c|c|c|c|}
\hline Predictor & Univariable & Full model & Final model \\
\hline \multicolumn{4}{|l|}{ Age group } \\
\hline $18-59$ years & Ref. & Ref. & Ref. \\
\hline$>59$ years & $3.94(3.16-4.91)$ & $4.57(3.63-5.75)$ & $4.54(3.64-5.66)$ \\
\hline \multicolumn{4}{|l|}{ Sex } \\
\hline Female & Ref. & Ref. & \\
\hline Non-Hispanic White & Ref. & Ref. & \\
\hline Black & $1.32(0.89-1.95)$ & $1.42(0.96-2.12)$ & \\
\hline Hispanic & $0.82(0.57-1.19)$ & $0.99(0.68-1.42)$ & \\
\hline Asian and other & $1.03(0.66-1.61)$ & $0.94(0.59-1.48)$ & \\
\hline \multicolumn{4}{|l|}{ Tumor location } \\
\hline Spinal cord & Ref. & Ref. & Ref. \\
\hline Less than gross total & Ref. & Ref. & Ref. \\
\hline Debulking (gross total or radical) & $0.53(0.42-0.66)$ & $0.63(0.49-0.83)$ & $0.63(0.50-0.80)$ \\
\hline \multicolumn{4}{|l|}{ Histology } \\
\hline Low-grade ependymoma & Ref. & Ref. & Ref. \\
\hline Anaplastic ependymoma & $4.28(3.27-5.61)$ & $2.91(2.13-3.97)$ & $2.97(2.22-3.97)$ \\
\hline \multicolumn{4}{|l|}{ Radiation therapy } \\
\hline No & Ref. & Ref. & \\
\hline Yes & $2.13(1.72-2.65)$ & $1.22(0.97-1.56)$ & \\
\hline
\end{tabular}

\section{Discussion}

This study provides strong evidence that treatment type and tumor location are important prognostic factors in ependymoma survival. While the prognostic value of these factors is not particularly surprising, it is interesting to note that there may be key differences between pediatric and adult cases in how such factors impact survival. Furthermore, age at diagnosis appears to be a strong predictor, with the extremes of age ( $<5$ or $>59$ years) displaying the worst survival, despite adjustment for covariates.

Exactly which factors have the strongest influence on ependymoma survival remains an elusive topic, despite prior research $[2,6,7]$. One reason why it is difficult to determine the true prognostic value of potential predictors is that most such factors are biologically and clinically interrelated. For example, infratentorial tumors tend to be harder to resect completely [20], compared to supratentorial tumors, and they are more common in children than adults. Therefore, if children with infratentorial tumors are found to have worse survival, a simplistic analysis of such data would not be able to resolve whether the poor prognosis was due primarily to the tumor location (infratentorial), the margin of surgical resection, or the younger age of the patients [20]. Even adjustment for such factors in a multivariable model may not totally resolve the problem, as residual confounding (or higher-order interactions) may still be present. While stratifying by age and tumor location may give a better estimate of the effect of total versus partial resection in this scenario, most studies of ependymoma lack a study population large enough to support analyses stratified on multiple variables. Thus, although there is much clinical insight to be gained from case series, several larger studies utilizing multistrategic approaches are necessary to be able to ascertain a valid estimate of the effect of each potential predictor. 

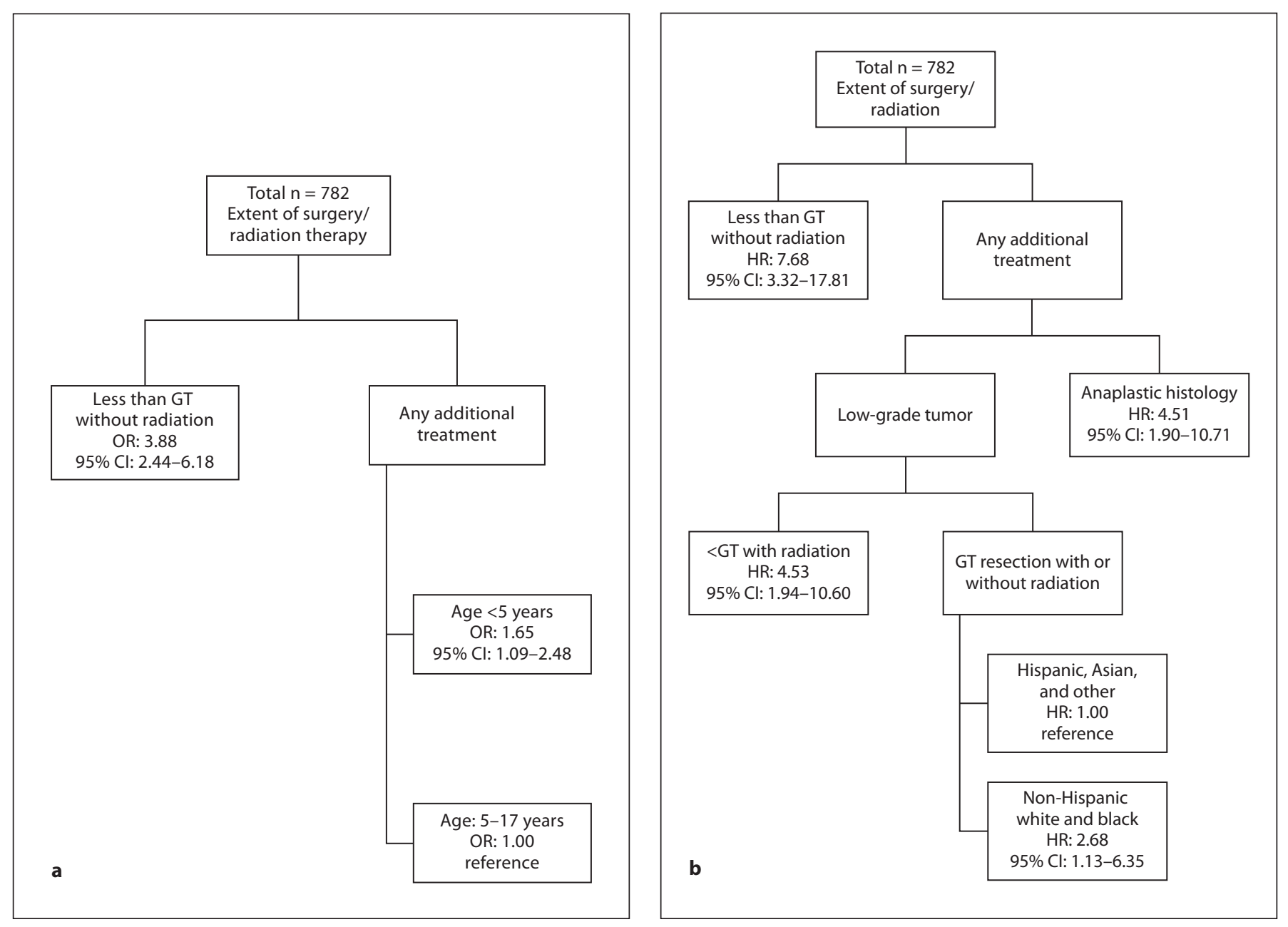

Fig. 1. a CART showing predictors of mortality among pediatric ependymoma cases. b TBSA results for pediatric ependymoma.

A few other studies have also capitalized on available SEER data to identify potential prognostic factors for ependymoma $[9,13]$. One such study found that age and tumor location were significantly associated with survival, using the 1973-2003 dataset [9]. However, this study did not provide results from a fully-adjusted multivariable model, which can be problematic for the reasons discussed above. Another such study did provide adjusted risk estimates (analyzing cases of all ages) [13], but did not employ recursive partitioning to hone in on the most important sets of characteristics involved in predicting ependymoma prognosis. In addition to using more recent data, our study utilizes a multistrategic approach to help clarify the complex network of factors that drive survival in these patients.

Despite prior research, the roles of most potential predictors of mortality among ependymoma patients still remain somewhat controversial $[2,20]$, potentially due to the aforementioned issues. However, some trends have emerged in the literature with relative consistency. Intracranial tumor location and treatment type, especially surgical margin, have previously been implicated as important prognostic factors $[7,9,10,13,21]$. In our study, children with spinal cord tumors did appear to have a better prognosis than children with intracranial tumors (table 2). However, treatment type was more consistently predictive than tumor location across different analytical approaches (i.e. Cox, CART, and TBSA). Conversely, among adults, tumor location proved to be a very influential factor both in the Cox regression model and in the regression trees, with supratentorial tumors conferring worse prognosis. Although treatment type also had considerable impact on survival among 
Fig. 2. a CART showing predictors of mortality among adult ependymoma cases.

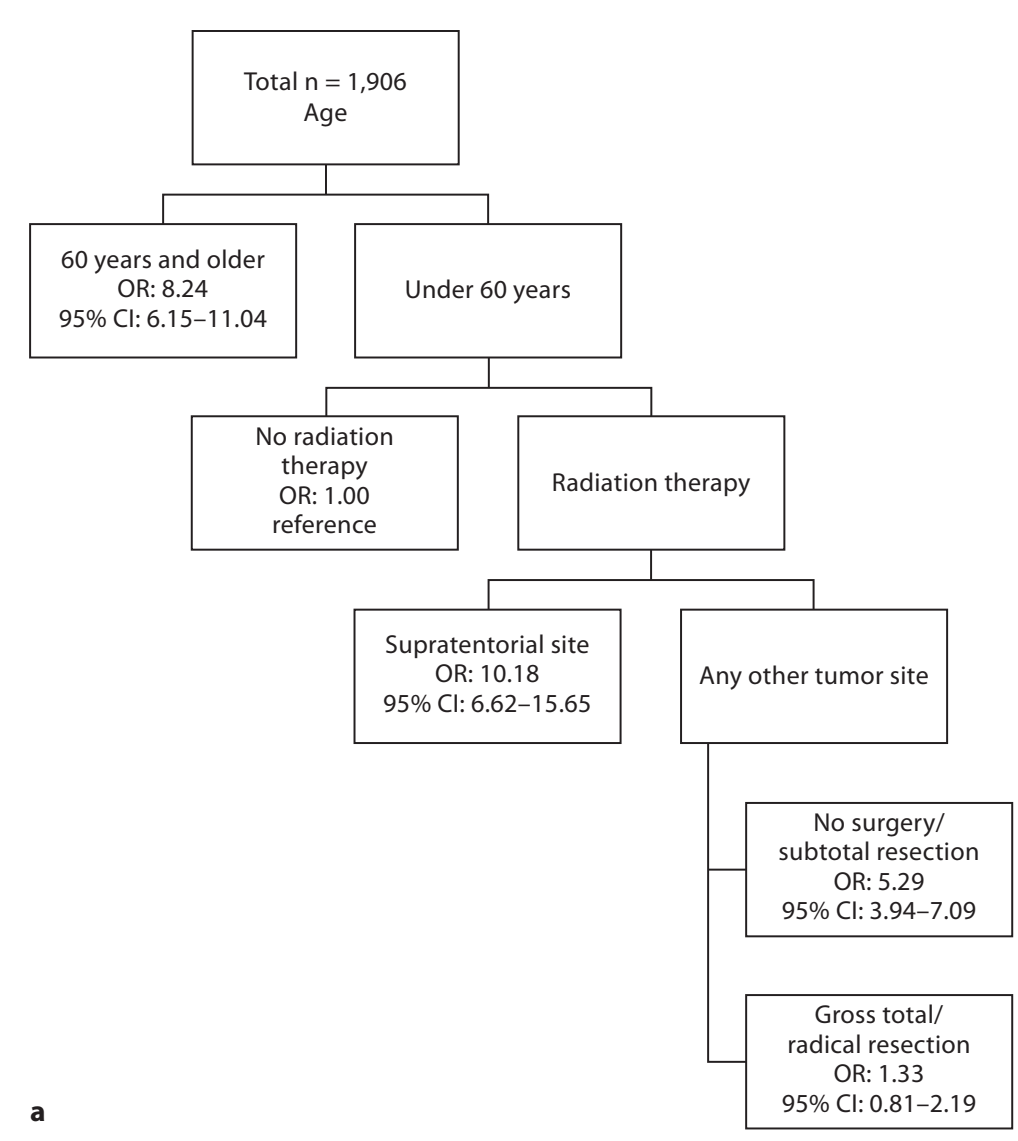

adults, it was less influential than tumor site in our models.

The most effective treatment seemed to be complete resection. In children, complete resection without radiation had the most protective effect. However, among children with subtotal resection, there was an implication that radiation therapy may afford some additional protection, although the effect estimate was not statistically significant (table 2). Although other studies have also suggested that there may be a benefit of radiation therapy for pediatric cases $[9,22]$, this finding needs to be confirmed in larger studies, as adverse cognitive effects are possible [20]. Interestingly, our analyses implied that radiation therapy among adults might be somewhat deleterious to survival (table 3; fig. 2). However, this is likely due to confounding by indication, in that the clinical decision to treat the patients with radiation therapy may have been made because these patients were believed to have a poorer prognosis. Therefore, the effect of radiation therapy warrants further investigation, specifically in a randomized controlled trial in order to better account for baseline patient characteristics.

Previous research has also indicated that tumor histology influences survival in ependymoma patients [2]. In our study, we found that individuals with anaplastic tumors had worse survival than those with low-grade ependymomas (tables 2, 3; fig. 1b, 2b), particularly among adults. Compared to having a low-grade ependymoma, having an anaplastic tumor was associated with an almost 3 times higher mortality risk in adults (table 3), whereas among children, having an anaplastic ependymoma was associated with a $51 \%$ higher mortality risk, compared to having a low-grade tumor (table 2).

Our analyses have some limitations typical of studies using registry data. One such limitation is that tumor characteristics could not be confirmed by a study pathologist. Although about $97.5 \%$ of diagnoses were microscopically confirmed, there may still be some misclassi- 


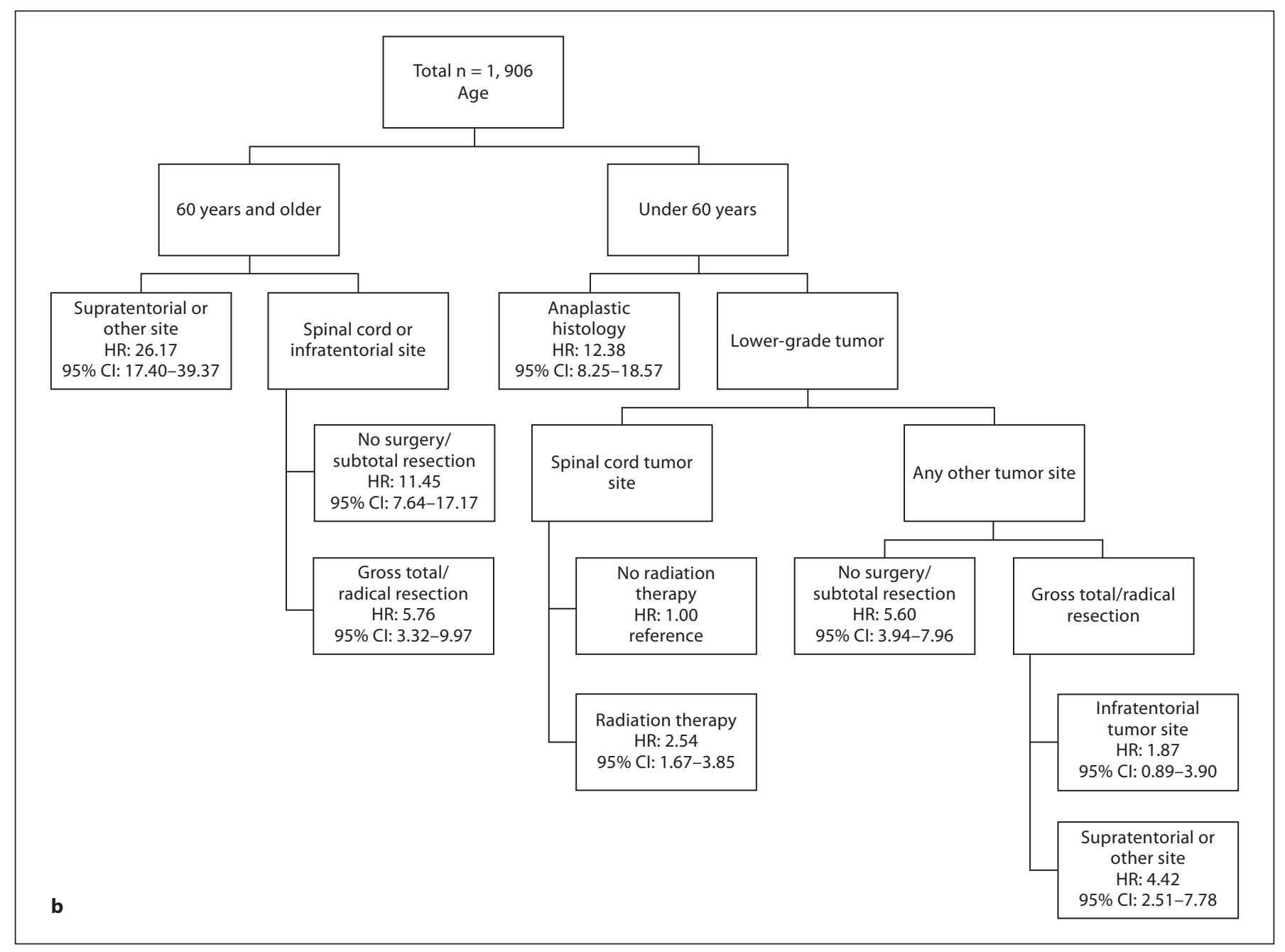

Fig. 2. b TBSA results for adult ependymoma.

fication present in our study. However, tumor heterogeneity seems to be a problem even for ependymoma studies with central pathologic review because of a lack of clear diagnostic criteria $[2,6,11]$. Furthermore, it would have been helpful to have information on chemotherapy and radiation dose, neither of which are provided in SEER. Despite the use of this national resource, some of our analyses, particularly those among the pediatric cases (table 2), were somewhat underpowered, as indicated by wide confidence intervals. Finally, it is possible that these analyses do not reflect the impact of the most recent changes (post-2000) in the clinical management of ependymoma, both because of the lack of detailed treatment information in SEER and because there has not been enough follow-up time since these changes to be able to effectively analyze their influence.
In conclusion, although our results are not completely unexpected based on the previous literature, our study utilizes sophisticated statistical analyses to provide additional evidence that tumor site, age, treatment modality, and tumor histology are important predictors of survival among ependymoma cases. Having a tumor in the supratentorial region of the brain conferred the worst survival in adults, whereas infratentorial tumors were more hazardous in children. Furthermore, tumor histology was more influential in adults than children, and complete resection was the most effective treatment option, regardless of age. However, several topics, such as the impact of radiation therapy and whether prognostic factors for older adults differ from those for younger patients, still deserve further clarification. 


\section{Acknowledgments}

This work was supported by a grant from the National Cancer Institute (K07CA131505 to M.E.S.). We also acknowledge the Collaborative Ependymoma Research Network (CERN).

\section{Disclosure Statement}

M.R. Gilbert served on advisory boards for Genentech and Schering-Plough, from which he has also received research support. No other conflicts of interest relevant to these analyses were declared.

\section{References}

1 Gurney JG, Smith MA, Bunin GR: CNS and miscellaneous intracranial and intraspinal neoplasms. SEER Pediatr Monogr 1995 http://seer.cancer.gov/publications/childhood/cns.pdf. Accessed on 5-4-2011.

2 Reni M, Gatta G, Mazza E, Vecht C: Ependymoma. Crit Rev Oncol Hematol 2007;63:8189.

3 McCarthy BJ, Dolecek TA, Danciu OC, Villano JL: Descriptive epidemiology of ependymal tumors in the United States (abstract). J Clin Oncol 2010;28:e12524.

4 McGuire CS, Sainani KL, Fisher PG: Incidence patterns for ependymoma: a surveillance, epidemiology, and end results study. J Neurosurg 2009;110:725-729.

$\checkmark 5$ Korshunov A, Golanov A, Sycheva R, Timirgaz $\mathrm{V}$ : The histologic grade is a main prognostic factor for patients with intracranial ependymomas treated in the microneurosurgical era: an analysis of 258 patients. Cancer 2004;100:1230-1237.

-6 Armstrong TS, Vera-Bolanos E, Bekele BN, Aldape K, Gilbert MR: Adult ependymal tumors: prognosis and the M. D. Anderson Cancer Center experience. Neuro Oncol 2010;12:862-870.

7 Gilbert MR, Ruda R, Soffietti R: Ependymomas in adults. Curr Neurol Neurosci Rep 2010;10:240-247.

8 Weber DC, Zilli T, Do HP, Nouet P, Gumy Pause F, Pica A: Intensity modulated radiation therapy or stereotactic fractionated radiotherapy for infratentorial ependymoma in children: a multicentric study. J Neurooncol 2011;102:295-300.
9 McGuire CS, Sainani KL, Fisher PG: Both location and age predict survival in ependymoma: a SEER study. Pediatr Blood Cancer 2009;52:65-69.

10 Metellus P, Guyotat J, Chinot O, Durand A, Barrie M, Giorgi R, Jouvet A, FigarellaBranger D: Adult intracranial WHO grade II ependymomas: long-term outcome and prognostic factor analysis in a series of 114 patients. Neuro Oncol 2010;12:976-984.

11 Gupta N, Banerjee A, Haas-Kogan D: Pediatric CNS Tumors, ed 2. Berlin, Springer, 2010.

- 12 Metellus P, Barrie M, Figarella-Branger D, Chinot O, Giorgi R, Gouvernet J, Jouvet A, Guyotat J: Multicentric French study on adult intracranial ependymomas: prognostic factors analysis and therapeutic considerations from a cohort of 152 patients. Brain 2007;130:1338-1349.

13 Rodriguez D, Cheung MC, Housri N, Quinones-Hinojosa A, Camphausen K, Koniaris LG: Outcomes of malignant CNS ependymomas: an examination of 2,408 cases through the Surveillance, Epidemiology, and End Results (SEER) database (1973-2005). J Surg Res 2009;156:340-351.

14 McLaughlin MP, Marcus RB Jr, Buatti JM, McCollough WM, Mickle JP, Kedar A, Maria BL, Million RR: Ependymoma: results, prognostic factors and treatment recommendations. Int J Radiat Oncol Biol Phys 1998;40: 845-850.
15 Reni M, Brandes AA, Vavassori V, Cavallo G, Casagrande F, Vastola F, Magli A, Franzin A, Basso U, Villa E: A multicenter study of the prognosis and treatment of adult brain ependymal tumors. Cancer 2004;100:1221-1229.

16 LeBlanc M, Crowley J: Relative risk trees for censored survival data. Biometrics 1992;48: 411-425.

17 Lemon SC, Roy J, Clark MA, Friedmann PD, Rakowski W: Classification and regression tree analysis in public health: methodological review and comparison with logistic regression. Ann Behav Med 2003;26:172-181.

18 Segal M: Regression trees for censored data. Biometrics 1988;44:35-47.

19 van Putten W: CART: Stata module to perform classification and regression tree analysis. Statistical Software Components. Boston College Department of Economics, 2006. http://econpapers.repec.org RePEc:boc: bocode:s456776. Accessed on 12-15-2010.

-20 Tamburrini G, D’Ercole M, Pettorini BL, Caldarelli M, Massimi L, Di Rocco C: Survival following treatment for intracranial ependymoma: a review. Childs Nerv Syst 2009;25:1303-1312.

21 Rousseau P, Habrand JL, Sarrazin D, Kalifa C, Terrier-Lacombe MJ, Rekacewicz C, Rey A: Treatment of intracranial ependymomas of children: review of a 15-year experience. Int J Radiat Oncol Biol Phys 1994;28:381386

22 Koshy M, Rich S, Merchant TE, Mahmood U, Regine WF, Kwok Y: Post-operative radiation improves survival in children younger than 3 years with intracranial ependymoma. J Neurooncol 2011;105:583-590. 